\title{
Erratum to: Empagliflozin: A Review of Its Use in Patients with Type 2 Diabetes Mellitus
}

\author{
Lesley J. Scott
}

Published online: 27 November 2014

(C) Springer International Publishing Switzerland 2014

Erratum to: Drugs (2014) 74:1769-1784

DOI 10.1007/s40265-014-0298-1

Page 1777, column 2, section 4.4, paragraph 2, lines

3-8: The following sentence, which previously read:

"At 52 weeks, adjusted mean changes from baseline in daily insulin dose were significantly lower in the empagliflozin 10 and $25 \mathrm{mg}$ groups than in the placebo group $(+1.3$ and -1.1 vs. +10.2 IU/day; both $p<0.01)$; respective baseline mean daily doses were $90.4,89.4$ and 99.5 IU/day [38]."

should read:

"At 78 weeks, adjusted mean changes from baseline in daily insulin dose were significantly lower in the empagliflozin 10 and $25 \mathrm{mg}$ groups than in the placebo group $(-1.21$ and -0.47 vs. $+5.45 \mathrm{IU} /$ day; both $p<0.01)$; respective baseline mean daily doses were $45.13,48.43$ and 47.84 IU/day [38].”

The online version of the original article can be found under doi:10.1007/s40265-014-0298-1.

L. J. Scott $(\bowtie)$

Springer, Private Bag 65901, Mairangi Bay 0754, Auckland,

New Zealand

e-mail: demail@springer.com 